\title{
Tyrosine kinase activity of EphA2 promotes its 5897 phosphorylation and glioblastoma cell proliferation
}

$\operatorname{AUTHOR}(S)$ :

Hamaoka, Yuho; Negishi, Manabu; Katoh, Hironori

\section{CITATION:}

Hamaoka, Yuho ...[et al]. Tyrosine kinase activity of EphA2 promotes its $\mathbf{8 9 9 7}$ phosphorylation and glioblastoma cell proliferation. Biochemical and Biophysical Research Communications 2018, 499(4): 920-926

ISSUE DATE:

2018-05-23

URL:

http://hdl.handle.net/2433/231897

\section{RIGHT:}

(c) 2018. This manuscript version is made available under the CC-BY-NC-ND 4 . license

http://creativecommons.org/licenses/by-nc-nd/4.0/. The full-text file will be made open to the public on 23 May 2019 in accordance with publisher's 'Terms and Conditions for Self-Archiving'. This is not the published version. Please cite only the published version.この論文は出版社版でありません。引用の際には出版社版をご確認ご利用ください。 


\section{Tyrosine kinase activity of EphA2 promotes its S897 phosphorylation and glioblastoma cell proliferation}

Yuho Hamaoka ${ }^{\mathrm{a}}$, Manabu Negishi ${ }^{\mathrm{a}, \mathrm{b}}$, and Hironori Katoh ${ }^{\mathrm{a}, \mathrm{b}}$

${ }^{\text {a }}$ Laboratory of Molecular Neurobiology, Graduate School of Pharmaceutical

Sciences, Kyoto University, Yoshidakonoe-cho, Sakyo-ku, Kyoto 606-8501, Japan

${ }^{b}$ Laboratory of Molecular Neurobiology, Graduate School of Biostudies, Kyoto University, Yoshidakonoe-cho, Sakyo-ku, Kyoto 606-8501, Japan

Address all correspondence to Hironori Katoh, Laboratory of Molecular

Neurobiology, Graduate School of Biostudies, Kyoto University, Yoshidakonoe-cho, Sakyo-ku, Kyoto 606-8501, Japan

Tel: +81-75-753-7687; Fax: +81-75-753-7688

E-mail address: hirokato@pharm.kyoto-u.ac.jp 


\section{Abstract}

EphA2, a member of the Eph family of receptor tyrosine kinases, has been reported to promote tumor malignancy through phosphorylation of serine 897 (S897). Here, we found that overexpression of wild-type EphA2 induced S897 phosphorylation through ERK activation without growth factors or cytokines and promoted glioblastoma cell proliferation. However, overexpression of a kinase-inactive mutant of EphA2 failed to induce ERK activation, S897 phosphorylation, and promotion of glioblastoma cell proliferation. These data suggest that when overexpressed, EphA2 induces ERK activation through its tyrosine kinase activity, leading to S897 phosphorylation and promotion of glioblastoma cell proliferation. Our findings provide a new insight into how EphA2 mediates glioblastoma progression.

Keywords: EphA2, ERK, cell proliferation, glioblastoma 


\section{Abbreviations}

BrdU, bromodeoxyuridine

EGF, epidermal growth factor

ICD, inter cellular domain

PI3K, phosphatidylinositol 3-kinase

PKA, protein kinase A

RSK, p90 ribosomal S6 kinase

RTK, receptor tyrosine kinase

S897, serine 897

WT, wild type 


\section{Introduction}

Eph receptors constitute the largest family of receptor tyrosine kinases (RTKs). Binding with their membrane-bound ligand ephrins induces activation of their tyrosine kinase activity and trans-phosphorylation of the receptors, creating docking site for cytoplasmic signaling proteins. Eph receptors and ephrins affect diverse cellular mechanisms such as cellular cytoskeleton, cellular motility, morphology, proliferation, and apoptosis, and they play versatile roles during development and tissue homeostasis. For example, they mediate orchestration of the cell positioning, tissue and organ patterning during development, regulation of axon guidance, synapse plasticity, tissue remodeling, bone morphogenesis, and angiogenesis [1-3].

Dysregulation of the Eph receptor/ephrin system is associated with acquisition of tumorigenic properties, tumor growth and metastasis [1-3]. Overexpression of Eph receptors have been reported in various types of cancers. In particular, EphA2 is frequently overexpressed in a variety of human cancers such as glioblastoma, melanoma, ovarian, lung, prostate, 
breast, colorectal, gastric, bladder, and renal cell carcinomas, and the increased expression level correlates with the advanced grade of such cancers, and with poor patient survival [4-11]. Thus, EphA2 has been featured as a critical tumorigenic and tumor-promoting factor.

The signaling mechanisms underlying EphA2-mediated cancer promotion are under studied. Ligand binding-mediated EphA2 signaling (canonical signaling) in cancer cells has been shown to suppress tumor adhesion, migration, and proliferation [12-14], whereas in some cases, the canonical signaling is reported to promote tumor dissemination through inducing cell retraction [15,16], and angiogenesis [17-19]. Thus, the outcome of the canonical signaling in cancer depends on the cell type and the microenvironment. Another pathway mediated by EphA2 is the ligand independent (non-canonical) signaling which requires phosphorylation of EphA2 on serine 897 (S897), a residue in the linker segment connecting the kinase and SAM domains. Recently, Akt, RSK, and PKA have been reported to phosphorylate EphA2 S897, promoting the cancer cell motility, invasion, 
and progression [20-22]. Because S897 phosphorylation is critical for EphA2-mediated tumor malignant alteration, it is important to elucidate the mechanisms underlying the regulation of S897 phosphorylation of EphA2. EphrinA1-induced signaling is reported to reduce the S897 phosphorylation of EphA2 [20]. However, it is also reported that ephrinA1 stimulation does not change S897 phosphorylation level, and that S897 phosphorylation and tyrosine phosphorylation of EphA2 coexist [22]. Thus, the relationship between the tyrosine kinase activity and S897 phosphorylation of EphA2 remains to be solved. In the present report, we show that EphA2 overexpression induces ERK activation through its tyrosine kinase activity, leading to S897 phosphorylation of EphA2 and promotion of the glioblastoma cell proliferation.

\section{Materials and Methods}

\section{Plasmids}

EphA2-WT (Wild-type EphA2), EphA2-KM (K646M mutant) and 
EphA2-SA (S897A mutant) were subcloned into pcDNA3 vectors (Life Technologies) as described previously [23,24]. Flag-tagged EphA2-ICD (Intercellular domain of EphA2 encoding residues 560-976) was constructed by PCR-mediated mutagenesis and subcloned into the $\mathrm{pCXN} 2$ vector. The YFP expression vector (pCAG) [25] was a generous gift from Drs. J. Miyazaki (Osaka University, Osaka, Japan) and T. Saito (Chiba University, Chiba, Japan).

\section{Reagents and Antibodies}

The pharmacological MEK inhibitor U0126 and phosphatidylinositol 3-kinase (PI3K) inhibitor LY294002 were purchased from Merck Millipore, and the Akt inhibitor MK-2206 was from ChemieTech. We used the following antibodies in this study: rabbit monoclonal antibodies against EphA2 (D4A2), S897 phospho-EphA2 (D9A1), Y588 phospho-EphA2 (D7X2L), ERK, and T202/Y204 phospho-ERK, (Cell Signaling Technology); a mouse monoclonal antibody against Flag (M2) 
(Sigma); a mouse monoclonal antibody against BrdU (3D4) (BD

Biosciences); secondary antibodies conjugated to horseradish peroxidase

(DAKO); Alexa Fluor 488-conjugated anti-GFP and Alexa Fluor 594conjugated goat anti-mouse IgG (Thermo Fisher Scientific).

\section{Cell culture and transfection}

U-251 cell line was obtained from European Collection of Cell Cultures (ECACC). A172 cell line was provided by the RIKEN BRC through the National Bio-Resource Project of the MEXT, Japan. U-251, A172, HeLa and HEK293T cells were grown in Dulbecco's modified Eagle's medium containing $10 \%$ fetal bovine serum, $4 \mathrm{mM}$ glutamine, 100 units $/ \mathrm{ml}$ of penicillin, and $0.1 \mathrm{mg} / \mathrm{ml}$ of streptomycin under humidified air containing $5 \% \mathrm{CO}_{2}$ at $37^{\circ} \mathrm{C}$. Cells were transfected with indicated plasmids using polyethyleneimine MAX (for HEK293T and HeLa cells) or Lipofectamine 2000 (Invitrogen; for A172 cells), according to the manufacturer's instructions. 


\section{Bromodeoxyuridine (BrdU) incorporation}

A172 cells cultured on coverslips were treated with $\operatorname{BrdU}(10 \mu \mathrm{M})$

for $5 \mathrm{~h}$ and fixed with $4 \%$ paraformaldehyde in PBS for $20 \mathrm{~min}$ at room temperature. To identify BrdU-incorporated cells, cells were pretreated with $4 \mathrm{~N} \mathrm{HCl}$ in PBS for $5 \mathrm{~min}$ at room temperature. Cells were then incubated with $0.2 \%$ Triton X-100 in PBS for 10 min and with $10 \%$ fetal bovine serum in PBS for $30 \mathrm{~min}$ to block nonspecific antibody binding. Cells were incubated with anti-BrdU antibody in PBS overnight at $4^{\circ} \mathrm{C}$, followed by incubation with Alexa Fluor 594-conjugated anti-mouse IgG antibody together with Alexa Fluor 488-conjugated anti-GFP antibody for $1 \mathrm{~h}$ at room temperature. After washing with PBS, cells were mounted in $90 \%$ glycerol containing $0.1 \%$ p-phenylenediamine dihydrochloride in PBS. Images were acquired using a Nikon Eclipse E800 microscope equipped with a 20x objective, and the number of BrdU-positive and/or YFP-positive cells was counted. The percentage of BrdU-labeled YFP-positive cells in the total 
number of YFP-positive cells (BrdU+YFP+/YFP+) was shown.

\section{Immunoblotting}

Cell lysates were separated by SDS-PAGE and electrophoretically transferred onto a polyvinylidene difluoride membrane (Millipore Corporation). The membrane was blocked with 3\% low fat milk in Trisbuffered saline, and then incubated with primary antibodies. The primary antibodies were detected with horseradish peroxidase-conjugated secondary antibodies and enhanced chemiluminescence (ECL) detection kit (GE Healthcare).

\section{Data analysis}

Densitometry analysis was performed with ImageJ free image analysis software (National Institutes of Health), and phospho-ERK/total ERK and phospho-S897 EphA2/total EphA2 ratio were determined. Statistical significance was established using the two-sample Student's $t$ test 
or the analysis of variance (ANOVA) and post hoc test (Tukey) (KaleidaGraph version 4.5.2, Synergy Software). $p<0.05$ was considered significant.

\section{Results}

EphA2 S897 phosphorylation is enhanced by its tyrosine kinase activity.

To investigate the relationship between S897 phosphorylation of EphA2 and its tyrosine kinase activity, HEK293T cells were transfected with either wild-type EphA2 (EphA2-WT), EphA2-S897A (EphA2-SA), or a kinase-inactive mutant EphA2-K646M (EphA2-KM) (Fig.1A), and the cell lysates were immunoblotted with anti-pS897-EphA2 and anti-pY588EphA2 antibodies to compare the levels of EphA2 S897 and Y588 phosphorylation. When overexpressed, EphA2 phosphorylates its tyrosine residues including Y588, and its tyrosine kinase activity is increased in the absence of ephrins [26-28]. We found that overexpression of EphA2-WT and EphA2-SA showed similar levels of Y588 phosphorylation, whereas 
overexpression of EphA2-KM did not. On the other hand, overexpression of EphA2-WT also induced S897 phosphorylation without growth factor stimulation. However, the level of S897 phosphorylation in EphA2-KM was weak and significantly lower than in EphA2-WT (Fig. 1B, C). These results suggest that S897 phosphorylation of EphA2 is promoted by its tyrosine kinase activity. To further investigate the mechanism underlying EphA2 overexpression-induced S897 phosphorylation, we compared the level of S897 phosphorylation in EphA2-WT and in a mutant lacking the extracellular and transmembrane domain of EphA2 (EphA2-intercellular domain, EphA2-ICD) (Fig. 1D). Using HeLa cells in which endogenous EphA2 is phosphorylated on S897 in response to EGF stimulation, S897 of EphA2-ICD was also phosphorylated (Fig. 1E), indicating that EphA2-ICD retains the ability to be phosphorylated on S897. However, overexpression of EphA2-ICD by itself did not induce S897 phosphorylation. (Fig. 1F) These results suggest that the functional extracellular and transmembrane domains are required for EphA2 overexpression-induced S897 
phosphorylation.

\section{EphA2 induces ERK activation through its tyrosine kinase activity.}

We next determined how S897 phosphorylation is promoted by tyrosine kinase activity of EphA2. Because EphA2 is reported to enhance the RAS-MAPK signaling [29,30], we examined whether the RAS-MAPK signaling was associated with EphA2 overexpression-induced S897 phosphorylation. HEK293T cells were transfected with EphA2-WT, EphA2KM, EphA2-SA, or EphA2-ICD and the cell lysates were immunoblotted with anti-pERK antibody. Overexpression of either EphA2-WT or EphA2SA induced ERK phosphorylation. However, EphA2-KM overexpression failed to induce ERK phosphorylation (Fig. 2A, B), suggesting that EphA2 induces ERK activation through its tyrosine kinase activity rather than S897 phosphorylation. On the other hand, overexpression of EphA2-ICD also failed to induce ERK phosphorylation (Fig. 2C, D).

EphA2 is highly expressed in glioblastoma, and its expression level 
correlates with poor survival of patients [4-7,31,32]. We next investigated whether endogenously overexpressed EphA2 also induced ERK activation. We used glioblastoma U-251 cells, which express a high level of EphA2 among the glioblastoma cell lines. U-251 cells were exposed to ephrinA1$\mathrm{Fc}$ for $24 \mathrm{~h}$ in order to downregulate expression of EphA2 as previously described $[33,34]$. We found that downregulation of EphA2 in U251 cells by long exposure to ephrinA1-Fc reduced the phosphorylation level of ERK (Fig. 2E, F), indicating that high expression of endogenous EphA2 causes ERK activation.

\section{ERK activation is required for EphA2-induced S897 phosphorylation.}

EphA2 is reported to be phosphorylated by RSK downstream of the MEK/ERK signaling in response to inflammatory cytokine or growth factor stimulation $[21,34]$. We next investigated whether ERK activation mediates EphA2 overexpression-induced S897 phosphorylation. Treatment with a MEK inhibitor U0126 impaired S897 phosphorylation induced by 
overexpression of EphA2-WT (Fig. 3A). Although Akt is also reported to phosphorylate EphA2 S897 in some cell lines [20,23,35,36], treatment with an Akt inhibitor MK2206 or its upstream PI3K inhibitor LY294002 had no effect on EphA2 overexpression-induced S897 phosphorylation (Fig. 3B). Taken together, these results suggest that activation of the MEK/ERK signaling pathway is required for the EphA2-induced S897 phosphorylation.

\section{EphA2 promotes glioblastoma cell proliferation through its tyrosine}

\section{kinase activity.}

We have previously reported that phosphorylation of EphA2 on S897 by RSK downstream of EGF stimulation promotes glioblastoma cell proliferation [34]. To examine the contribution of EphA2 tyrosine kinase activity to the promotion of glioblastoma cell proliferation, we analyzed cell proliferation by BrdU incorporation. To evaluate the effect of EphA2 overexpression, we used glioblastoma A172 cells, which express EphA2 relatively lower than U-251 cells. A172 cells were transfected with either 
EphA2-WT, EphA2-KM, or EphA2-ICD, together with YFP. Overexpression of EphA2-WT increased the number of BrdU-positive cells, whereas overexpression of EphA2-KM or EphA2-ICD, both of which failed to induce the S897 phosphorylation, did not (Fig.4 A, B). These results indicate that tyrosine kinase activity of EphA2 and the functional extracellular and transmembrane domains are required for the EphA2 overexpression-induced promotion of glioblastoma cell proliferation.

\section{Discussion}

In this study, we demonstrate the relationship between the tyrosine kinase activity of EphA2 and its S897 phosphorylation in the regulation of glioblastoma cell proliferation. Overexpression of EphA2 stimulates its tyrosine kinase activity and induces ERK activation, which results in S897 phosphorylation, leading to the promotion of glioblastoma cell proliferation (Fig 4C). Thus, our results provide a new insight into how EphA2 mediates the malignant progression of glioblastoma and other types of cancers with 
high expression of EphA2.

Glioblastoma is the most common malignant brain tumor [37].

Despite the therapeutic advances, it still has a severely poor prognosis with

a dismal median survival of 15-17 months, being one of the most lethal human cancers $[38,39]$. Therefore, revealing the oncogenic mechanisms of glioblastoma is required for its novel therapy. EphA2 is frequently overexpressed in glioblastoma, and the expression level of EphA2 correlates with the poor survival of the patients [4-7,31,32], suggesting that EphA2 may be an attractive target for glioblastoma therapy. Previous studies have shown that EphA2 contributes to glioblastoma progression through S897 phosphorylation. Phosphorylation of EphA2 on S897 by Akt downstream of growth factor stimulation was originally reported to promote glioblastoma cell migration [20], and to contribute to the maintenance of stem-like tumorpropagating cells in glioblastoma [40]. In addition, a recent report has shown that EphA2 S897 is phosphorylated by RSK downstream of cytokines in multiple cancer cell lines including glioblastoma [21], suggesting that the 
regulation of EphA2 S897 phosphorylation depends on cell type and cellular context. We previously reported that epidermal growth factor stimulation induced the phosphorylation of EphA2 on S897 through the MEK/ERK/RSK pathway and promoted glioblastoma cell proliferation [34]. In the present report, EphA2 overexpression induced its S897 phosphorylation without growth factor or cytokine stimulation and, as a result, promoted glioblastoma cell proliferation. Thus, EphA2 overexpression as well as growth factor stimulation seems to play an important role during glioblastoma progression. On the other hand, our results show that EphA2 overexpression induces ERK activation. Because activation of ERK has been reported to promote EphA2 expression [41], it is possible that there is a positive feedback mechanism between EphA2 expression and ERK activation that promotes glioblastoma progression. Furthermore, since overexpression of EphA2 is reported to correlate with tumor malignancy in multiple types of cancers [4-11], the signaling we show in the present report may contribute to the progression of such cancers. 
Tyrosine kinase of EphA2 can be activated both in a liganddependent and in a ligand-independent manner. EphA2 phosphorylates itself on three regulatory tyrosine residues and directly enhances its catalytic activity by modulating the structure of its kinase domain to allow ATP and substrates to access the activate site [26-28]. Ligand-activated EphA2 causes ubiquitination and degradation of EphA2, while, the autonomous activation of EphA2 does not [42], suggesting some differences in signaling mechanisms between the autonomous activation and ligand stimulation. Previous studies have reported that expression of a kinase inactive mutant of EphA2 suppresses the malignant phenotype of breast cancer cells [43], and that EphA2, which is overexpressed in HER2 tyrosine kinase inhibitors (TKI) -resistant breast cancer cells and EGFR TKI-resistant lung cancer cells, enhances the therapeutic resistance through its tyrosine kinase activity $[44,45]$. Using EphA2-KM tyrosine kinase-inactive mutant, we found that the tyrosine kinase activity of EphA2 promotes its S897 phosphorylation and glioblastoma cell proliferation. Taken together, these findings suggest that 
inhibitors of EphA2 kinase activity may offer an effective therapeutic approach for tumors exhibiting high EphA2 expression.

Another EphA2 mutant we used in this report was EphA2-ICD consisting only of EphA2 cytosolic domain. Overexpression of EphA2-ICD failed to induce S897 phosphorylation and ERK activation. It would be interesting to investigate why EphA2-ICD has no ability to induce ERK activation for understanding the regulation of S897 phosphorylation. One possibility is that localization of EphA2 at the cell membrane may be required for EphA2-induced ERK activation, because EphA2 is reported to interact with proteins on or near the membrane such as FAK [5], PI3K [13], ErbB2 [30], and LRP1 [36]. Another possible mechanism is that the extracellular domain of EphA2 may be required. A recent report showed that cleavage of EphA2 extracellular domain by MT1-MMP induces RhoA activation, promoting breast cancer cell invasion [47]. Thus, structural changes in the extracellular domain of EphA2 may be important for transducing some cellular signals. In future studies, it will be interesting to 
investigate the effects of EphA2 localization and the extracellular domain on S897 phosphorylation.

\section{Acknowledgments}

We thank Dr. J. Miyazaki and Dr. T. Saito for the EYFP expression plasmid. This work was supported by Grants-in-aid for Scientific Research from the Ministry of Education, Science, Sports, and Culture of Japan (15K07043).

\section{Author Contributions}

YH, MN, and HK conceived and designed the study; $\mathrm{YH}$ and $\mathrm{HK}$ performed the experiments. $\mathrm{YH}$ analyzed data. $\mathrm{YH}$ and $\mathrm{HK}$ wrote the manuscript.

\section{References}

[1] E.B. Pasquale, Eph receptors and ephrins in cancer: bidirectional signaling and beyond, Nat. Rev. Cancer 10 (2010) 165-180.

[2] A.W. Boyd, P.F. Bartlett, M. Lackmann, Therapeutic targeting of EPH 
receptors and their ligands, Nat. Rev. Drug Discovery 13 (2014) 39-62.

[3] A. Kania and R. Klein, Mechanisms of ephrin-Eph signaling in development, physiology and disease, Nat. Rev. Mol. Cell Biol. 17 (2016) 240-256.

[4] J. Wykosky, W. Debinski, The EphA2 receptor and ephrinA1 ligand in solid tumors: function and therapeutic targeting, Mol. Cancer Res. 6 (2008) 1795-1806.

[5] J. Wykosky, D.M. Gibo, C. Stanton, W. Debinski, EphA2 as a novel molecular marker and target in glioblastoma multiform, Mol. Cancer Res. 3 (2005) 541-551.

[6] F. Liu, P.J. Park, W. Lai, E. Maher, A. Chakravarti, et al., A genome-wide screen reveals functional gene clusters in the cancer genome and identified EphA2 as a mitogen in glioblastoma, Cancer Res. 66 (2006) 10815-10823.

[7] L.F. Wang, E. Fokas, M. Bieker, F. Rose, P. Rexin, et al., Increased expression of EphA2 correlates with adverse outcome in primary and recurrent glioblastoma multiform patients, Oncol. Rep. 19 (2008) 151156.

[8] A.R. Hess, E.A. Seftor, L.M. Gardner, K. Carles-Kinch, G.B. Schneider, et al., Molecular regulation of tumor cell vasculogenic mimicry by tyrosine phosphorylation: role of epithelial cell kinase (Eck/EphA2), Cancer Res. 61 (2001) 3250-5.

[9] P.H. Thaker, M. Deavers, J. Celestino, A. Thornton, M.S. Fletcher, et al., EphA2 expression is associated with aggressive features in ovarian carcinoma, Clin Cancer Res 10 (2004) 5145-5150.

[10] M.S. Kinch, M.B. Moore, and D. Harpole, Predictive value of the EphA2 receptor tyrosine kinase in lung cancer recurrence and survival, Clin Cancer Res 9 (2003) 613-618.

[11] G. Zeng, Z. Hu, M.S. Kinch, C.X. Pan, D.A. Flockhart, et al., High-level expression of EphA2 receptor tyrosine kinase in prostatic intraepithelial neoplasia. Am. J. Pathol. 163 (2003) 2271-2276.

[12] N.Y. Yang, C. Fernandez, M. Richter, Z. Xiao, F. Valencia, et al., 
Crosstalk of the EphA2 receptor with a serine/threonine phosphatase suppress the Akt-TORC1 pathway in cancer cells. Cell. Signal. 23 (2011) 201-212.

[13] H. Miao, E. Burnett, M. Kinch, E. Simon and B. Wang, Activation of EphA2 kinase suppress integrin function and causes focal-adhesionkinase dephosphorylation. Nat. Cell. Biol. 2 (2000) 62-69.

[14] H. Miao, B.R. Wei, D.M. Peehl, Q. Li, T. Alexandrou, et al., Activation of EphA receptor tyrosine kinase inhibits the Ras/MAPK pathway. Nat. Cell. Biol. 3 (2001) 527-530.

[15] M. Parri, F. Buricchi, E. Giannoni, G. Grimaldi, T. Mello, et al., EphrinA1 Activates a Src/Focal Adhesion Kinase-mediated motility response leading to Rho-dependent Actino/Myosin contractility, J. Biol. Chem. 282 (2007) 19619-19628.

[16] J.W. Astin, J. Batson, S. Kadir, J. Charlet, R.A. Persad, et al., Competition amongst Eph receptors regulates contact inhibition of locomotion and invasiveness in prostate cancer cells, Nat. Cell. Biol. 12 (2010) 1194-1204.

[17] D.M. Brantley-Sieders, W.B. Fang, Y. Hwang, D. Hicks, and J. Chen, Ephrin-A1 facilitates mammary tumor metastasis through an angiogenesis-dependent mechanism mediated by EphA receptor and Vascular Endothelial Growth Factor in Mice, Cancer Res. 66 (2006) 10315-10324.

[18] D.M. Brantley, N. Cheng, E.J. Thompson, Q. Lin, R.A. Brekken, et al., Soluble Eph A receptors inhibit tumor angiogenesis and progression in vivo. Oncogene 21 (2002) 7011-26.

[19] P. Dobrzanski, K. Hunter, S. Jones-Bolin, H. Chang, C. Robinson, et al., Antiangiogenic and antitumor efficacy of EphA2 receptor antagonist, Cancer Res. 64 (2004) 910-919.

[20] H. Miao, D.Q. Li, A. Mukherjee, H. Guo, H. Petty, et al., EphA2 mediates ligand-dependent inhibition and ligand-independent promotion of cell migration and invasion via a reciprocal regulatory loop with Akt, Cancer Cell 16 (2009) 9-20. 
[21] Y. Zhou, N. Yamada, T. Tanaka, T. Hori, S. Yokoyama, et al., Crucial roles of RSK in cell motility by catalyzing serine phosphorylation of EphA2, Nat. Commun. 6 (2015) 7679.

[22] A. Barquilla, I. Lamberto, R. Noberini, S. Heynen-Genel, LM. Brill, et al., Protein kinase A can block EphA2 receptor-mediated cell repulsion by increasing EphA2 S897 phosphorylation. Mol.Biol. Cell 27 (2016) $2757-2770$.

[23] K. Harada, M. Negishi and H. Katoh, HGF-induced serine 897 phosphorylation of EphA2 regulates epithelial morphogenesis of MDCK cells in 3D culture, J. Cell Sci. 128 (2015) 1912-1921.

[24] H. Kawai, M. Kobayashi, N. Hiromoto-Yamaki, K. Harada, M. Negishi, and H. Katoh, Ephexin4-mediated promotion of cell migration and anoikis resistance is regulated by serine 897 phosphorylation of EphA2, FEBS Open Bio 3 (2013) 78-82.

[25] H. Niwa, K. Yamamura, J. Miyazaki, Efficient selection for highexpression transfectants with a novel eukaryotic vector, Gene 108 (1991) 193-200.

[26] C. Ellis, F. Kasmi, P. Ganju, E. Walls, G. Panayotou, et al., A juxta membrane autophosphorylation site in the Eph family receptor tyrosine kinase, Sek, mediates high affinity interaction with p59fyn, Oncogene 12 (1996) 1727-1736.

[27] K.L. Binns, P.P. Taylor, F. Sicheri, T. Pawson, and S.J. Holland, Phosphorylation of tyrosine residues in the kinase domain and juxtamembrane region regulates the biological and catalytic activities of Eph receptors, Mol. Cell Biol. 20 (2000) 4791-4805.

[28] S. Wiesner, L.E.W. Groot, N. Warner, H. Lin, T. Pawson, et al., A change in conformational dynamics underlies the activation of Eph receptor tyrosine kinases, EMBO J. 25 (2006) 4686-4696.

[29] R. L. Pratt, and M.S. Kinch, Activation of the EphA2 tyrosine kinase stimulates the MAP/ERK kinase signaling cascade, Oncogene. 21 (2002) 7690-7699. 
[30] D.M. Brantley-Sieders, G. Zhuang, D. Hicks, W.B. Fang, Y. Hwang, J. M.M. Cates, et al., The receptor tyrosine kinase EphA2 promotes mammary adenocarcinoma tumorigenesis and metastatic progression in mice by amplifying ErbB2 signaling. J. Clin. Invest. 118 (2008) 64-78.

[31] M. Nakada, Y. Hayashi, J. Hamada, Role of Eph/ephrin tyrosine kinase in malignant glioma, Neuro. Oncol. 13 (2011) 1163-1170.

[32] B.W. Day, B.W. Stringer, A.W. Boyd, Eph receptors as therapeutic targets in glioblastoma, Br. J. Cancer 111 (2014) 1255-1261.

[33] J. Walker-Daniels, D.J. Riese II, M.S. Kinch, c-Cbl-dependent EphA2 protein degradation is induced by ligand binding, Mol. Cancer Res. 1 (2002) 79-87.

[34] Y. Hamaoka, M. Negishi, H. Katoh, EphA2 is a key effector of the MEK/ERK/RSK pathway regulating glioblastoma cell proliferation, Cell. Signal. 28 (2016) 937-945.

[35] H. Kawai, M. Kobayashi, N. Hiromoto-Yamaki, K. Harada, M. Negishi, and H. Katoh, Ephexin4-mediated promotion of cell migration and anoikis resistance is regulated by serine 897 phosphorylation of EphA2, FEBS Open Bio 3 (2013) 78-82.

[36] U. Gopal, J.E. Bohonowych, C. Lema-Tome, A. Liu, E. GarrettMayer, et al., A novel extracellular Hsp90 mediated co-receptor function for LRP1 regulates EphA2 dependent glioblastoma cell invasion, PLoS One 6 (2011) e17649.

[37] T.A. Dolecek, J.M. Propp, N.E. Stroup, and C. Kruchko, CBTRUS statistical report: primary brain and central nervous system tumors diagnosed in the United States in 2005-2009, Neuro Oncol. 14 (2012) v1-49.

[38] R. Stupp, W.P. Mason, M.J. van den Bent, et al. Radiotherapy plus concomitant and adjuvant temozolomide for glioblastoma, N. Engl. J. Med. 352 (2005) 987-96.

[39] D.R. Johnson, and B.P. O'Neill, Glioblastoma survival in the United States before and during the temozolomide era, J. Neuro Oncol. 107 (2012) 359-64. 
[40] E. Binda, A. Visioli, F. Giani, G. Lamorte, M. Copetti, et al., The EphA2 receptor drives self-renewal and tumorigenicity in Stem-like Tumor-Propagating Cells from Human Glioblastomas, Cancer Cell 22 (2012) 765-780.

[41] M. Macrae, R.M. Neve, P. Rodriguez-Viciana, C. Haqq, J. Yeh, et al., A conditional feedback loop regulates Ras activity through EphA2, Cancer Cell 8 (2005) 111-118.

[42] O. Sabet, R. Stockert, G. Xouri, Y. Bruggemann, A. Stanoev, et al., Ubiquitination switches EphA2 vesicular traffic from a continuous safeguard to a finite signaling mode, Nat. Commun. 6 (2015) 8047.

[43] W.B. Fang, D.M. Brantley-Sieders, M.A. Parker, A.D. Reith, and J. Chen, A kinase-dependent role for EphA2 receptor in promoting tumor growth and metastasis, Oncogene 24 (2005) 7859-7868.

[44] G. Zhuang, D.M. Brantley-Sieders, D. Vaught, J. Yu, L. Xie, S. Wells, et al., Elevation of receptor tyrosine kinase EphA2 mediates resistance to Trastuzumab therapy, Cancer Res. 70 (2010) 299-308.

[45] K.R. Amato, S. Wang, L. Tan, A.K. Hastings, W. Song, et al., EPHA2 blockade overcomes acquired resistance to EGFR kinase inhibitors in lung cancer, Cancer Res. 76 (2016) 305-318.

[46] A. Pandey, D.F. Lazar, A.R. Saltiel, and V.M. Dixit, Activation of the Eck receptor protein tyrosine kinase stimulates Phosphatidylinositol 3kinase activity, J Biol Chem. 269 (1994) 30154-30157.

[47] N. Sugiyama, E. Gucciardo, O. Tatti, M. Varjosalo, M. Hyytiainen, et al., EphA2 cleavage by MT1-MMP triggers single cancer cell invasion via homotypic cell repulsion, J. Cell Biol. 201 (2013) 467-484. 


\section{Figure legends}

Fig. 1. EphA2 S897 phosphorylation is enhanced by its tyrosine kinase activity.

A, D. The EphA2 constructs used in this study. LBD, ligand binding domain; C, Cysteine rich domain; FN, fibronectin III repeats; TM, transmembrane; KD, kinase domain; SAM, sterile- $\alpha$-motif. Numbers indicate amino acid position within the sequence.

B, F. Cell lysates from HEK293T cells transfected with the indicated plasmids were immunoblotted with the indicated antibodies.

C. Densitometry analysis was performed with ImageJ software, and the pS897 EphA2/ EphA2 ratio was determined. Data are the means \pm SD of three independent experiments $\left({ }^{*} \mathrm{p}<0.05 ; t\right.$ test $)$.

E. HeLa cells transfected with Control or Flag-tagged EphA2-ICD were treated with EGF $(100 \mathrm{ng} / \mathrm{ml})$ for $10 \mathrm{~min}$, and the cell lysates were analyzed by immunoblotting with the indicated antibodies. 
Fig. 2. EphA2 induces ERK activation through its tyrosine kinase activity.

A, C. Cell lysates from HEK293T cells transfected with the indicated plasmids were immunoblotted with the indicated antibodies.

B, D. Densitometry analysis was performed with ImageJ software and the $\mathrm{pERK} /$ ERK ratio was determined. Data are the means $\pm \mathrm{SD}$ of three independent experiments $\left({ }^{* *} \mathrm{p}<0.01, * * * \mathrm{p}<0.001\right.$, one-way ANOVA, Tukey's HSD post hoc test).

E. U-251 cells were treated with control-Fc or ephrinA1-Fc $(1 \mu \mathrm{g} / \mathrm{ml})$ for $24 \mathrm{~h}$, and the cell lysates were analyzed by immunoblotting with the indicated antibodies.

F. Densitometry analysis was performed with ImageJ software and the pERK/ERK ratio was determined. Data are the means $\pm \mathrm{SD}$ of three independent experiments $(* * \mathrm{p}<0.01, * * * \mathrm{p}<0.001$, one-way ANOVA, Tukey's HSD post hoc test).

Fig. 3. ERK activation is required for EphA2-induced 5897 phosphorylation. 
A. HEK293T cells were transfected with control or EphA2-WT, and treated with U0126 $(20 \mu \mathrm{M})$ for $15 \mathrm{~h}$. Cell lysates were analyzed by immunoblotting with the indicated antibodies.

B. HEK293T cells were transfected with control or EphA2-WT, and treated with MK2206 $(1 \mu \mathrm{M})$ or LY294002 $(20 \mu \mathrm{M})$ for $15 \mathrm{~h}$. Cell lysates were analyzed by immunoblotting with the indicated antibodies.

Fig. 4. EphA2 promotes glioblastoma cell proliferation through its tyrosine kinase activity.

A, B. A172 cells were transfected with YFP and the indicated plasmids. Then cells were stained with anti-BrdU and anti-GFP antibodies. The number of BrdU-positive and/or YFP-positive cells was counted, and the percentage of BrdU-labeled YFP-positive cells in the total number of YFPpositive cells $(\mathrm{BrdU}+\mathrm{YFP}+\mathrm{YFP}+)$ was shown. Data are the means $\pm \mathrm{SD}$ of seven independent experiments $(* * \mathrm{p}<0.01, * * * \mathrm{p}<0.001$, one-way ANOVA, Tukey's HSD post hoc test). 
C. Overexpression of EphA2 stimulates its tyrosine kinase activity and induces ERK activation, which results in S897 phosphorylation, leading to the promotion of glioblastoma cell proliferation. 
E-LAn IAIT $E$

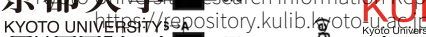

EphA2-KM
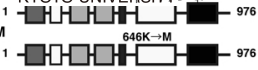

B

EphA2 - WT SA KM
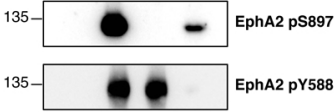

EphA2 pY588

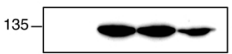

EphA2

( $\mathrm{kDa})$

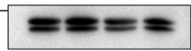

ERK

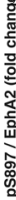

0.2

0

EphA2

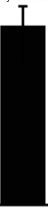

WT
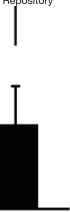

KM

$\mathbf{F}$

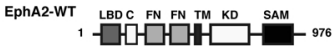

EphA2-ICD

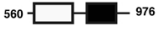

E

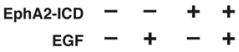

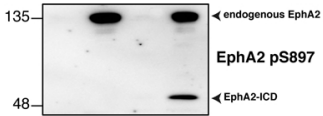

EphA2 - WT ICD
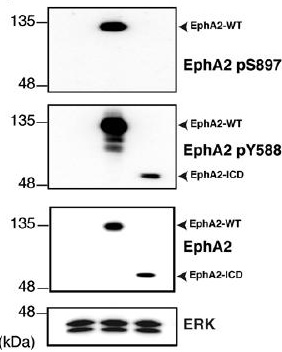

ERK 
A solf-archived $\mathbf{B}$

Copy in京都大学学術情報リポジトリ

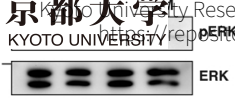

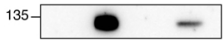

EphA2 pS897

135

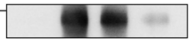

EphA2 pY588

135

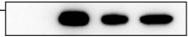

EphA2

(kDa)

C

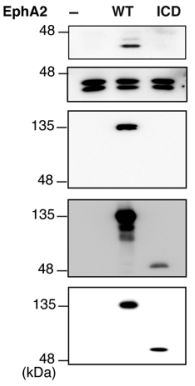

pERK

ERK

EphA2 pY588

EphA2 pS897

EphA2

E

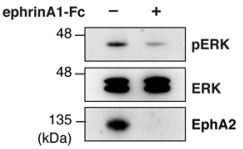

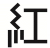

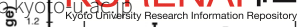

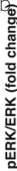

EphA2

WT

SA

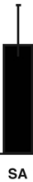

D

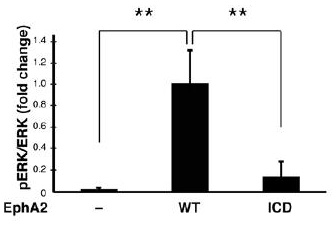

F

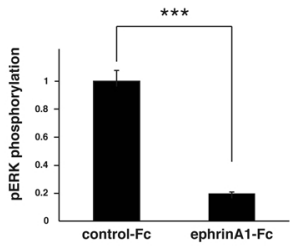

Figure 2 


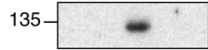

EphA2 pS897

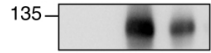

EphA2 pY588

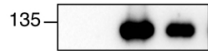

EphA2

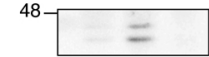

pERK

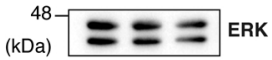

京都大学学術情報リボジトリ

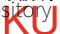

Kyo

$+\underset{+}{+}+$
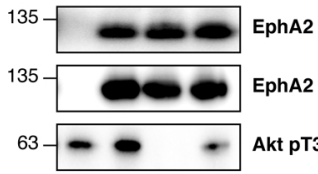

Akt pT308

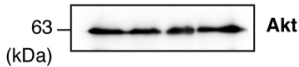



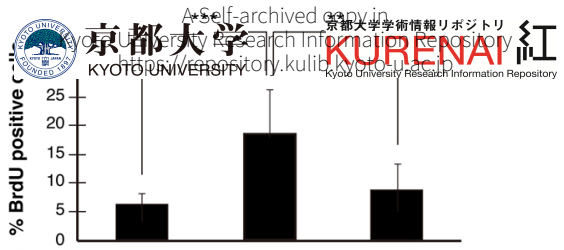

EphA2

B

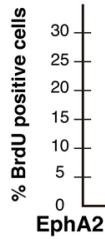

n.s.

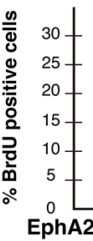

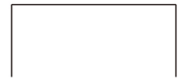

KM

C

Low expression of EphA2

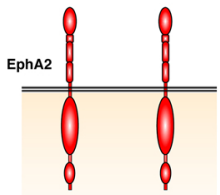

ERK
High expression of EphA2

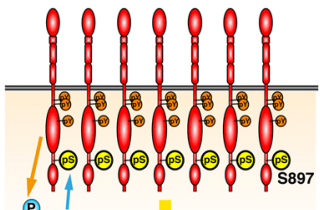

(P)
ICD

\section{ERK}

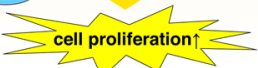

Figure 4 